\title{
Psyhoemotional Aspects for Creative Potential Development within the Framework of Schoolchildren Informational Culture Environment
}

\author{
Gulbanu T. Abitova ${ }^{1, \#, *}$, Mariyam K. Bapayeva,"\#, Zaini T. Koksheeva ${ }^{3, \#,}$ \\ Anar A. Kapenova ${ }^{4, \#}$ and Zeynekul D. Utepbergenova ${ }^{2, \#}$ \\ ${ }^{1}$ Almaty Branch of Saint-Petersburg University of the Humanities and Social Sciences, Almaty, Republic of \\ Kazakhstan \\ ${ }^{2}$ Kazakh National Women's Pedagogical University, Almaty, Republic of Kazakhstan \\ ${ }^{3}$ Yessenov University, Aktau, Republic of Kazakhstan \\ ${ }^{4}$ Zhetysu State University named after I. Zhansugurov, Taldykorgan, Republic of Kazakhstan
}

\begin{abstract}
Objective: In the process of creativity, the child develops intellectually and emotionally, determines its attitude towards life and its place in life, acquires the experience of collective interaction, improves its skills in working with various tools and materials.

Background: At present times, which most researchers refer to as the era of "creative information culture", the potential for creative development of students is of interest to both scientists and teachers. This paper considers creativity as a child's sense-creating ability, as a student's ability to form a model of the surrounding microcosm in the consciousness, which most often develops based on reading and processing information. This feature determines the uniqueness of the value-semantic attitude of children with inclusion to the world in general and to information, in particular.

Method: The study used materials from textbooks and manuals. Learning programs for children with developmental standards were studied. The level of students' creative thinking was tested. Methods for its development are derived.

Results: Various sources of information make up such a picture of the child's world in which a certain value-semantic core is gradually formed. On extensive material through comparative analysis it is proved that the creative component is characterised by the manifestation of fantasy and imagination in all the diverse informational aspects; the need for new information; dedication to the process of cognition; the desire to master the basics of creative search activity; manifestation of independence in the selection of means and methods of cognition; desire for co-creation with adults. In the process of creativity, the child develops intellectually and emotionally, determines his attitude to life and his place in it, acquires the experience of collective interaction, and improves his skills in working with various tools and materials.

Conclusion: According to the author, it is an artistic and creative activity that actualises the inner potential of the child, reveals his creative abilities, allows us to define the artistic and creative self-realisation of a pre-schooler as an organised process of targeted pedagogical.
\end{abstract}

Keywords: Creative thinking, preschool age, intellectual and emotional development of a child, humanisation of the pedagogical process, interpersonal interaction.

\section{INTRODUCTION}

Children with mental retardation account for approximately $50 \%$ of under-performing students. For their training, special educational institutions have been created - schools and classes of correctional developmental education. In modern conditions, the problem of the development, upbringing, and education of such children are of particular psychological and pedagogical importance. One of the most acute is the issue of developing creativity. The problem of the formation of creative activity has been the subject of research by philosophers, psychologists, and educators for many years [1, 2].

*Address correspondence to this author at the Almaty Branch of SaintPetersburg University of the Humanities and Social Sciences, Almaty, Republic of Kazakhstan; Tel: +77272790761; E-mail: gul_abit@murdoch.in

\#These authors are equally contributed.
Socio-economic transformations in society dictate the need to form a creatively active person with the ability to effectively and innovatively solve new life problems. In modern pedagogy and psychology, a special role is given to the principle of humanisation in the education, upbringing, and development of each child, and priority is given to the focus on the development of the child's personality, talents, creativity, and abilities. Spontaneity and increased emotionality of children with special educational needs, their naïvety, and curiosity, constant "discoveries" of themselves and the world around them - all these features of pre-schoolers contribute to and determine the awakening and development of beginnings of creativity [3].

Mental retardation is described by a slow pace of mental development, personality immaturity, and 
coarse cognitive activity disorders. In most cases, mental retardation is described by persistent, albeit mild, intellectual insufficiency and a weakly pronounced tendency to compensation and reversible development, possible only in conditions of special training and education. Artistic and creative activity occupies an important place in the education of children with special needs. For example, thanks to a special emotional richness that awakens not only a variety of experiences, but also a figurative worldview, spiritual sensitivity and the desire for independent creative selfrealisation. This type of activity brings to the child's life an individual and distinctive vision of the world around him and its attitude to it [4]. At the same time, artistic and creative activity through the ability to recognise good, evil, love, hate, etc. develops the individuality of the child's personality, helps him master the basic moral standards. Realising its creative ideas, the child reflects in this both its life values and the characteristics of its personality.

The creative abilities of students with mental retardation have their individual features, which are conditioned by the mental development of children in this category (verbal, imaginative thinking, imagination, thought processes). The purpose of the study is to identify the influence of these features on the level of development of creative thinking and to find methods that will help maximise them.

\section{MATERIALS AND METHODS}

The study used materials from textbooks and manuals for teachers teaching children with inclusion. The methods of teaching and developing creativity in such children were considered. Also, training programs for children with developmental standards were studied. The existing methodologies were compared. To study the level of creativity in children with mental retardation, a testing method was used $-a$ test by $\mathrm{K}$. A. Heller [5]. Two subjects were used as stimulus tasks in the test: a newspaper and a wooden ruler. For a certain time (six minutes for each item), the subjects were asked to come up with as many different and unusual ways of using these items and write down the ideas on a special form. In processing, each response was categorised. With that, the answers that were meaningless and absurd, i.e., not feasible under any conditions, were not considered. The categorisation of the answers was performed in the direction from general to particular in three stages. With that, at all stages, each answer was assigned a special digital code. The German version of the three-stage categorisation of answers in the "Unusual Use" test developed in the Munich longitudinal study of giftedness was used as the framework for developing a system for categorising answers. A general assessment of the development of a person's creative abilities was carried out based on an analysis of 3 parameters: fluency, flexibility, and originality.

The test involved 50 children aged 10 to 12 years, who were divided into two groups - control and main. The main group included children with mental retardation, and the control group comprised students with normal mental development. The test results were summarised and used as the basis to identify the level of creativity of students with mental retardation. Through analysis and generalisation, the necessary criteria were identified to increase the level of creativity in children with inclusion. The paper provides a detailed description of algorithms for including children with disabilities in the educational process in order to develop their creative potential. Methods were developed that can be introduced into an inclusive educational process or made part of additional classes for children with mental retardation.

\section{RESULTS}

To investigate the level of creative giftedness of children with mental retardation, the "Unusual Use" test was carried out [5]. A general assessment of the level of development of the creative abilities of a person was carried out based on the analysis of the following parameters: fluency, flexibility, originality. The results obtained by the Heller method show significant differences on the scales: "Fluency" and "Originality" according to these scales, the indicators are higher for the main group. According to the "Fluency" scale, children with mental retardation from the main group showcase a rather high ability to create a large number of verbally formulated ideas, which indicates manifestations of the productivity of thinking. Since productivity is strongly associated with other creative thinking indicators, a high level of its indicator suggests a higher level of creativity in general. On the scale of "Originality", they displayed rather good results, but this is rather an indicator of violations of their mental development: since the answers were extremely original, even pretentious and not standard.

Thus, summarising the results of the study on the "Fluency" and "Originality" scales, we can state that children with mental retardation have creative giftedness, but it is conditioned by the specific features 


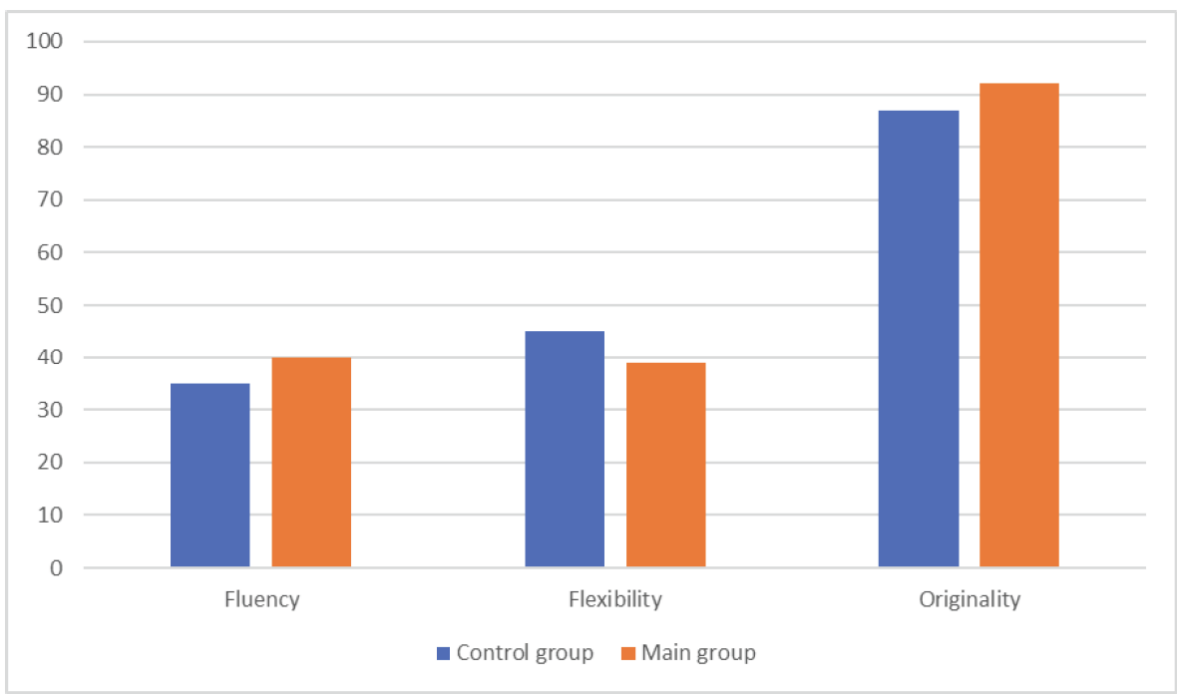

Figure 1: The Results of a Study of Creative Giftedness in Students with Mental Retardation.

of their mental development (Figure 1). To develop a creative type of thinking in such children, it is necessary to use various techniques in the learning process.

For the development of creative abilities in children with mental retardation or other types of inclusion, associated with problems in the development of intelligence, great potential lies in graphic and decorative activities, the use of non-conventional techniques (stained glass, collage of buttons, drawing with plasticine, a candle; papier-mâché, combined paper crafting). All these listed techniques attract with their artistic expressiveness, activate the individual abilities of children.

Visual activity is one of the first and most accessible means of self-expression of a child, in which the originality of many aspects of the child's psyche is manifested. The visual activity includes the following sections - modelling, application, drawing, and design. Drawing is a powerful means of cognition and reflection of reality, it reveals the features of imagination, the emotional-volitional sphere, thinking. Like a game, drawing allows the child to comprehend interesting stories better. Children draw what they think, what attracts their attention. Drawing is not only fun but also creative work.

Currently, technologies allow the use of various software to develop the creative potential of students with inclusion. The graphical editor Paint gives initial skills to work with all other graphic programs and contributes to the implementation of the independent creative process by pre-schoolers. The importance of forming the foundations of graphic literacy is dictated

Table 1: Algorithm for Working with the Graphical Editor Paint for Students with Mental Retardation and/or Other Inclusion

\begin{tabular}{|c|c|c|c|}
\hline $1^{\text {st }}$ stage & $2^{\text {nd }}$ stage & $3^{\text {rd }}$ stage & $4^{\text {th }}$ stage \\
\hline $\begin{array}{l}\text { Starting from the middle preschool } \\
\text { age, children with inclusion are } \\
\text { introduced to the computer's } \\
\text { picturesque, graphic capabilities. } \\
\text { With the help of developing tasks, } \\
\text { elementary skills are instilled in } \\
\text { drawing various lines on a } \\
\text { computer, filling out contours, } \\
\text { drawing geometric shapes, } \\
\text { choosing a colour, etc. At this stage, } \\
\text { it is important to adjust the work of } \\
\text { students, to teach them not just the } \\
\text { knowledge of a graphic editor, but } \\
\text { the ability to distinguish and use } \\
\text { various elements of the drawing. }\end{array}$ & $\begin{array}{l}\text { By performing tasks on drawing } \\
\text { on a computer in an } \\
\text { entertaining and playful way, } \\
\text { children learn graphic editors' } \\
\text { functions. Furthermore, they } \\
\text { get acquainted with visual } \\
\text { means and techniques in } \\
\text { practice and learn such } \\
\text { features as copying, } \\
\text { reproduction, and a reflection of } \\
\text { a picture or pattern. Mastering } \\
\text { these techniques helps the } \\
\text { child create their individual } \\
\text { simple artistic images with the } \\
\text { use of computer graphics. }\end{array}$ & $\begin{array}{l}\text { By using the capabilities } \\
\text { of computer graphics, } \\
\text { children learn to draw in } \\
\text { contrasting colours and } \\
\text { in shades of the same } \\
\text { colour, diminish and add } \\
\text { brightness, linking new } \\
\text { knowledge with their } \\
\text { feelings and emotions. } \\
\text { They learn to express } \\
\text { their emotions in this } \\
\text { way, explain their } \\
\text { condition through colour } \\
\text { or form, and select the } \\
\text { elements necessary for } \\
\text { this. }\end{array}$ & $\begin{array}{l}\text { Knowledge of colour, lines, volume, } \\
\text { rhythm is fixed by the creation of their } \\
\text { individual creative works, according to } \\
\text { their plan and their condition. This } \\
\text { helps children with mental retardation } \\
\text { reach their potential, express } \\
\text { emotions, understand the connection } \\
\text { between various objects in the real } \\
\text { world, and develop emotional } \\
\text { intelligence. However, it should be } \\
\text { noted that drawing on a computer } \\
\text { should be used only as an addition to } \\
\text { the conventional methods of training } \\
\text { and education and not replace the } \\
\text { actual modelling and application, } \\
\text { drawing, and graphics. }\end{array}$ \\
\hline
\end{tabular}


by its huge role in the development of logical thinking, cognitive abilities, spatial representations, and spatial imagination of pre-schoolers. It is advisable to introduce elements of graphic concepts in several ways, connecting them with the display of sensory images. The algorithm for working in a graphical editor designed for lessons looks as follows (Table 1).

By using information opportunities, the teacher must understand that they enrich the pedagogical process, and not cancel it. A prerequisite for computer creativity to become productive is the problematic situation, and it is impossible without the involvement of parents, teachers, and other children in the creative activity. A developing, emotionally comfortable environment when working on a computer must necessarily be complemented by interactive external and verbalcommunicative interpersonal interaction. In particular, the stimulus for the child's active inclusion in the search for ways out of the created problem based on information received on a computer should be a feeling of satisfaction from their own cognitive activity, wellformed questions of real people nearby, their reaction to what is happening and even their emotional state surprise, interest desire to overcome difficulties.

For the formation and development of creativity of children with retarded mental development, a pedagogical program was developed to form the foundations of the information culture of preschool children by means of socio-cultural activities, which is aimed at developing in children the basics of initial information knowledge, the selectivity of information consumption and understanding the importance of information for their own lives. The program aims to develop communicative activity and the meaningcreating abilities of children with retarded mental development, which are formed by interactive, information, and game technologies of socio-cultural activities. The key component of this program in our experimental work was the creation of the Smileys parent-child club with the aim of providing a single communicative space for communication, building a territory of creativity for children and parents to interact, developing, and strengthening friendly relations between them. The main objectives of the program were:

- $\quad$ the use of various means, forms, methods and technologies of socio-cultural activities to creatively encourage schoolers with retarded mental development to search, study the main sources of information and ways to work with them;
- appeal to information sources for joint solution and analysis of life problems, finding a way out of controversial situations;

- maintaining positive emotional contact with the interlocutor (the ability to listen to and understand the interlocutor, to correctly perceive and understand the information, to formulate one's judgment in response);

- $\quad$ creating a creative situation for the full realisation of potential opportunities and the development of leadership qualities of the child.

Highlighting the integration of the family and the preschool institution as the basis of the parent-child club, we emphasised the special mechanisms of interaction between parents and teachers, among which we should highlight the awareness of parents about the substantive aspects of family projects, voluntariness and the possibility of choosing to participate in the club, and a sense of success from participation in joint activities with children with retarded mental development. As experience has shown, attracting parents to partnerships has enabled them to realise the existing and acquire new experience in constructing their own parental behaviour, transmitting to children knowledge, attitudes, patterns of competent behaviour.

Thus, in preparation for the cognitive ring "Who knows your city better?", During the analysis and interpretation of the information received from magazines, encyclopaedias, educational television programs, and Internet resources, the children, along with their parents, learned interesting historical facts about the cultural life of their city. The result of presenting the information received in the process of the creative activity of pre-schoolers was the creation of mini-projects and presentations using descriptive stories of the sights and monuments of the city. As experience has shown, in the development of the communicative and creative abilities of preschool children, an effective way to integrate a preschool institution and a family is the joint project activity of teachers, parents, and children.

Thus, experience has shown that joint project activity is becoming a significant means of harmonising the creative space of children's lives, pedagogically appropriate influence on the family setting, integrating the activities of preschool institutions and the family in the development of communicative activity and creative 
abilities of pre-schoolers. It is known that a child actively responds to information received from various sources. Its perception of information is a mechanism for transforming stimuli coming from outside into motives aimed at creative cognition; it is capable of changing perceptions of the surrounding reality. This process creates a certain creative environment in which the child develops. This must take place in a professionally designed developmental environment that guides and helps the child strengthen and maintain a creative beginning.

An important mechanism for the formation of artistic and creative activities of children with special educational needs, affecting the formation of the foundations of information culture, are animated films. The cartoon is one of the carriers and translators of information about the world, about the norms of interaction and behaviour. However, their huge popularity and quite powerful influence on children is explained not only by the presence of such psychological mechanisms as infection, suggestion, and imitation. Animated films, firstly, demonstrate the emotional states of the characters, form stereotypes of behaviour and suggest ways out of difficult situations.

Secondly, cartoons provide a toolkit for action, simplify and visualise the standards of good and evil, good and bad, make it possible to understand the process of functioning of society in micro, mid-, macrostages through comparing itself with your favourite characters, and make it possible to overcome fears and difficulties. In addition, the imitation of heroes and the reproduction of events presented in cartoons, after a certain time, provide a choice of different roles for selfexpression and self-affirmation of the child, provide a variety of behavioural patterns in various communicative and informational situations of its life.

Thirdly, the study of the specific features of children's perception proved that a student with mental retardation, still having a fragmented perception, insufficient life, and aesthetic experience, after watching an animated film on the proposal to "play a cartoon or a hero" often reacts confusedly, its games often include only the external features of the cartoon characters - moves, gait, typical exclamations, that is, it does not see or cannot understand what was the authors' intended meaning that they tried to convey through a specific film product. Children with inclusion often do not reproduce the plot in the game, which in principle remains incomprehensible to them, with its opening, culmination, and denouement despite the fact that they watch the same cartoon several times, and their favourite ones - more than 15-20 times in a row.

There are a variety of techniques and methods for working with cartoons that contribute to the development of creative and critical thinking. For example, the reception of a "freeze-frame", where during the showing of the cartoon, at the moment of anxiety or conflict, the viewing stops and the audience is invited to express their opinion on further events, give their decision on what is happening and answer the questions: "Why did the main character do this?" , "And what would you do in their place?", "Give advice to the hero", "What are the difficulties of what is happening?", And then, the teacher offers to watch the cartoon further and see what was really what the hero actually did. Attention to animated films can be attracted through such creative tasks as "Come up with a script to continue the cartoon", "Draw a picture of the episode", "Write a letter to the hero", etc.

Another striking expression of the child's creativity can be the joint creation of a cartoon with adults. The most accessible and effective form for this is handdrawn cartoons. Pursuing the creation of animated films, the child receives unlimited opportunities for discoveries and new experiences, the development of its imagination, independence, and imaginative thinking. Children with special educational needs work in a creative team, which develops their sociability and trust, and achieving a common goal (creating a film) allows you to feel the effectiveness of this activity. Animated films enable the child to move to the development of associations and technologies through a combination of emotional, epistemological, hedonistic, intellectual, and psychological motives, and then through analysis of creativity.

As you can see, work on animated films has a significant impact on the formation of both the general cognitive activity of the child with special educational needs, the establishment of the foundations of its selfconsciousness, and the formation of individually significant and socially oriented qualities that are at the heart of the child's information culture. Thus, artistic and creative activity is a unique way of forming in children such important aspects of mental life as positive emotional well-being, creative thinking, artistic and creative abilities, thanks to which they lay the foundations of communicative activity and creativity. In the process of artistic and creative activity, the cognitive sphere not only expands but is also saturated with new knowledge, skills, creative potential, which, in 
turn, contributes to the formation of the foundations of the information culture of preschool children.

\section{DISCUSSION}

It is at preschool age, constantly comprehending, worrying over the meaning and depth of everything that he sees and hears the child forms the prerequisites not only for the motivational-personal component of its creativity but also for creating imagination. N.N. Poddyakov was the first who paid attention to this child's quality. In his opinion, the most important value is not in the result or product of creativity, but in the process of the formation of various types of activity, which means that in any activity and independent act of the child with special educational needs you can see small grains of creativity [6;7]. The same point of view is supported by V.T. Kudryavtsev, since, from his point of view, the preschool period is the period of the greatest activity of the child both in the activity itself and in the direct development of culture. He is convinced that the child's spiritual formation should be considered a special form of cultural creativity, as a certain process of building a culture of relations between the child and the world around him [8-10]. However, the scientist did not consider the influence of the cultural process on the development of the psyche of a child with inclusion. This study shows that the creative process allows developing the emotional intelligence and psyche of children with inclusion to a higher level.

An analysis of studies of the creativity of children with mental retardation in modern pedagogy and psychology allowed to draw a conclusion on the acceptability of a different approach to this concept. In our opinion, we consider children's creativity as a process that creates something new, which allows to develop a subjective, but still fairly ordered system of worldviews, which, in turn, contributes to the formation of a value attitude to culture and the development of the potential hidden due to delayed development of the psyche. At the same time, a child with inclusion, being a subject of active meaning-creating, productive, and transformative activity, also acts as the creator of culture [11]. According to L.S. Vygotsky, the desire of students with mental retardation and/or other inclusions to novelty describes artistic creativity, because by experimenting with materials, creating artistic images, children make "discoveries", they seek to acquire new knowledge, learn new presentation methods" [12].

On the basis of a comparative analysis of psychological and pedagogical literature, we formulated our definition of creativity as a child's sensecreating ability, in the future, we consider creativity as the ability of a pre-schooler to form in its mind a model of the surrounding microcosm, which develops most often on the basis of reading and processing information. This ability is determined by the uniqueness of the value-semantic attitude of children with retarded mental development to the world in general and to information in particular. Various sources of information make up such a picture of the child's world, in which a certain value-semantic core is gradually formed under the influence of information [13].

As a rule, the attention of scientists is focused on the study of the creative activity of children with normal intelligence $[14,15]$. In contrast, the study of students of secondary school age with mental retardation was conducted less consistently. The specifics of the development of the creative abilities of this category of schoolchildren have been understudied, and as a result, the creative abilities of children with mental retardation have not yet received sufficient scientific understanding. The recommendations offered by individual psychologists and teaching staff are contradictory and not sufficiently tested. In particular, the psychological and pedagogical literature has not yet presented a comprehensive approach to the study of creative abilities in schoolchildren with mental retardation. As a result of this, the question of the methods of developing creative abilities in this group of students remains open. This paper presents a study of the level of creativity of children with mental retardation and suggests methods for developing their creative potential.

\section{CONCLUSIONS}

The results of this work on the formation of the foundations of the information culture of children with inclusion, which reflect the personal contribution of the author to the solution of the stated problem, are as follows:

1. An analysis of theoretical and methodological approaches to the concept of "creativity of a student with inclusion" as a result of the cognitive and personal development of a child, capable of creative activity, which takes shape based on the value-semantic attitude of older preschool children towards the world in general and towards information, in particular. 
2. Determination of the factors of creativity of a child with mental retardation, including originality, speed, variability, flexibility.

3. Presentation of the pedagogical programme for the formation of the foundations of the information culture of pre-schoolers by means of socio-cultural activities aimed at developing the communicative activity and meaning-creating abilities of children, which are formed by interactive, informational, and gaming technologies of socio-cultural activity

The results of the study can be applied in sociocultural activities, inclusive education, and upbringing. The methods proposed in the study can help in the development of the creative potential of children with mental retardation. In conclusion, we can say that the topic of development in children with the inclusion of creative potentials requires more in-depth research. It is important to apply various techniques that contribute to the development of creativity in order to create a curriculum of inclusive education, including the development of the personal development of children with inclusion and their implementation through creativity.

\section{ACKNOWLEDGEMENT}

None.

\section{REFERENCES}

[1] Clarke R, Shaw-Ridley M. Parental attitudes and beliefs about pre-schooler preventive oral health behaviors: implications for health promotion. Journal of Immigrant and Minority Health 2019; 21(4): 731-36. https://doi.org/10.1007/s10903-018-0812-8
[2] Vygotsky LS. Education of mental activity in preschool children. Moscow: Pedagogika, 1983.

[3] Gaidareva IN. Socio-cultural environment as a factor of formation of information culture of personality. Maykop: Ayaks, 2002.

[4] Guildford D. Three sides of intelligence. The psychology of thinking. Moscow: Progress, 1965.

[5] Heller K, Procidano ME, Swindle RW. Experimental studies of the nature and effects of social support. In: New developments in research on life stress and social support. Montreal: American Psychological Association, 1980.

[6] Kazakova TG. Theory and methodology of the development of children's fine art. Moscow: Vlados, 2006.

[7] Kudryavtsev VT. Psychology of human development: The foundation of a cultural-historical approach. Riga: Eksperiment, 1999.

[8] Kudryavtsev VT. Creativity is the language of culture: how a child masters it. Pre-schooler. Methods and Practices of Education and Training 2012; 6: 5-13.

[9] Landis TD, Hart KC, Graziano PA. Targeting self-regulation and academic functioning among pre-schoolers with behavior problems: Are there incremental benefits to including cognitive training as part of a classroom curriculum? Child Neuropsychology 2019; 25(5): 688-704. https://doi.org/10.1080/09297049.2018.1526271

[10] Lunkenheimer E, Panlilio C, Lobo FM, Olson SL, Hamby CM. Pre-schoolers' self-regulation in context: task persistence profiles with mothers and fathers and later attention problems in kindergarten. Journal of Abnormal Child Psychology 2019; 47(6): 947-60. https://doi.org/10.1007/s10802-019-00512-x

[11] Melik-Pashaev AA. About the source of a person's ability to art. Psychology Issues 1998; 1: 76-82.

[12] Paramonova LA, Protasova EYu. Preschool and primary education abroad: History and present. Moscow: Izdatelskiy tsentr "Akademiya" 2001.

[13] Poddyakov AN. Development of research initiative in childhood. Moscow: Moscow State University, 2001.

[14] Podymova LS. Pedagogy. Moscow: Publishing House Yurait 2014.

[15] Smirnova EO. Child psychology. Moscow: Knorus, 2016.

Received on 25-07-2020

Accepted on 19-08-2020

Published on 14-09-2020

DOI: https://doi.org/10.6000/2292-2598.2020.08.03.17

(C) 2020 Abitova et al.; Licensee Lifescience Global.

This is an open access article licensed under the terms of the Creative Commons Attribution Non-Commercial License (http://creativecommons.org/licenses/by-nc/3.0/) which permits unrestricted, non-commercial use, distribution and reproduction in any medium, provided the work is properly cited. 